\title{
Carne caprina e sua utilização na elaboração de produtos cárneos: Uma revisão
}

\author{
Goat meat and its use in the production of meat products: A review
}

Carne de cabra y su uso en la producción de productos cárnicos: Una revisión

Recebido: 28/06/2021 | Revisado: 05/07/2021 | Aceito: 09/07/2021 | Publicado: 20/07/2021

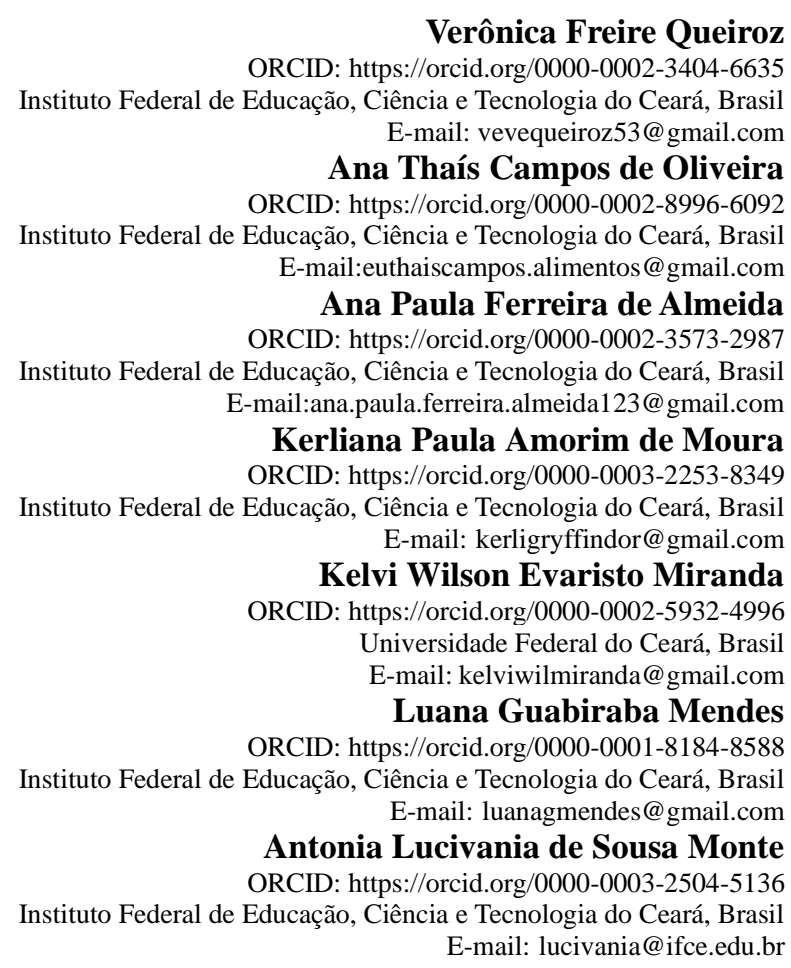

\section{Resumo}

Os consumidores estão mais exigentes quanto à qualidade dos produtos e seus benefícios à saúde, assim como a busca por alimentos mais práticos. Alimentos embutidos são apresentados em grande diversidade de categorias em mercado crescente. A carne de cabra (ou caprina), rica em proteínas e lipídios de boa qualidade, vem despertando o interesse dos consumidores, e motivado à pesquisas para produção e desenvolvimento de novos produtos cárneos. Este estudo objetivou identificar, através da literatura científica, as vantagens tecnológicas da carne caprina na utilização de produtos cárneos e suas influências sobre as características físico-químicas e sensoriais desses alimentos. Este estudo trata de uma revisão narrativa, cuja pesquisa de artigos foi realizada nas bases científicas de dados Science Direct, PubMed e Google acadêmico, utilizando os seguintes termos de busca: "sausage" OR "meat products" AND "goat meat". Foram incluídos artigos de pesquisa, disponibilizados na íntegra, gratuitos e que tivessem sido publicados entre os anos de 2019 e 2021. A literatura mostrou que a carne caprina é rica nutricionalmente e possui gorduras saudáveis e baixas calorias. Além disso, apresentou potencial tecnológico para elaboração de produtos cárneos, como salsichas, linguiças, nuggets, patês e hambúrgueres. Assim como, atuando como agente promovedor de mudanças nas características nutricionais, sensoriais e físico-químicas dos produtos. A carne caprina pode ser utilizada como uma das matérias primas no desenvolvimento de produtos cárneos com alto aproveitamento, valor agregado e potencial tecnológico, qualidade (sensorial e nutricional) e seguro.

Palavras-chave: Embutidos; Carne mista; Valor agregado; Alimentos saudáveis; Potencial tecnológico.

\begin{abstract}
Consumers are more demanding for the quality of products and their health benefits, as well as the search for more practical foods. Sausage foods are presented in a wide variety of categories in a growing market. Goat (or goat) meat, rich in good quality proteins and lipids, has been arousing the interest of consumers and motivating research for the production and development of new meat products. This study aimed to identify, through the scientific literature, the technological advantages of goat meat in the use of meat products and its influence on the physicochemical and sensory characteristics of these foods. This study is a narrative review, whose articles were searched in the scientific databases Science Direct, PubMed, and academic Google, using the following search terms: "sausage" OR "meat
\end{abstract}


products" AND "goat meat". A research article was included, available in full, free, and published between the years 2019 and 2021. The literature showed that goat meat is nutritionally rich and has healthy fats and low calories. In addition, it presented the technological potential for the elaboration of meat products, such as sausages, sausages, nuggets, pates, and hamburgers. As well as acting as a promoter of changes in the nutritional, sensory and physicochemical characteristics of the products. Goat meat can be used as one of the raw materials in the development of meat products with high utilization, added value and technological potential, quality (sensory and nutritional), and safe.

Keywords: Sausages; Mixed meat; Added value; Healthy food; Technological potential.

\section{Resumen}

Los consumidores son cada vez más exigentes con la calidad de los productos y sus beneficios para la salud, así como con la búsqueda de alimentos más prácticos. Los embutidos se presentan en una amplia variedad de categorías en un mercado en crecimiento. La carne de cabra, rica en proteínas y lípidos de buena calidad, ha despertado el interés de los consumidores y ha motivado la investigación para la producción y desarrollo de nuevos productos cárnicos. Este estudio tuvo como objetivo identificar, a través de la literatura científica, las ventajas tecnológicas de la carne de cabra en el uso de productos cárnicos y su influencia en las características fisicoquímicas y sensoriales de estos alimentos. Este estudio es una revisión narrativa, cuyos artículos fueron buscados en las bases de datos científicas Science Direct, PubMed y Academic Google, utilizando los siguientes términos de búsqueda: "salchicha" O "productos cárnicos" Y "carne de cabra". Se incluyó un artículo de investigación, disponible en su totalidad, gratuito y publicado entre los años 2019 y 2021. La literatura muestra que la carne de cabra es nutricionalmente rica y tiene grasas saludables y bajas calorías. Además, presentó el potencial tecnológico para la elaboración de productos cárnicos, como embutidos, chorizos, nuggets, patés y hamburguesas. Además de actuar como promotor de cambios en las características nutricionales, sensoriales y fisicoquímicas de los productos. La carne de caprino puede ser utilizada como una de las materias primas en la elaboración de productos cárnicos con alta utilización, valor agregado y potencial tecnológico, calidad (sensorial y nutricional) y segura.

Palabras clave: Embutidos; Carnes mixtas; Valor añadido; Comida saludable; Potencial tecnológico.

\section{Introdução}

Os consumidores modernos estão mais conscientes sobre o exigir por qualidade dos alimentos e benefícios para a saúde. $\mathrm{O}$ atual estilo de vida acelerado (fast lifestyle) enfatiza a importância e necessidade por alimentos práticos e de rápido preparo (fast food) como aqueles que são vendidos com descrição "produtos práticos e de fácil preparo" (Xue et al., 2020). Nas últimas décadas, as pessoas passaram a buscar mais por alimentos processados pré-cozidos e/ou prontos para consumo, levando a uma mudança nos hábitos alimentares (Kausar, Kausar, Khan, Haque, \& Azad, 2021).

Uma das fontes de proteína mais comum e importante é a carne, comercializada não apenas como produto fresco, mas também como carne processada (Dolch, Judas, Schwägele, \& Brüggemann, 2019). De acordo com o Decreto ${ }^{\circ} 9.013$, de 29 de março de 2017, produtos cárneos são aqueles obtidos de carnes, de miúdos e de partes comestíveis das diferentes espécies animais, com as propriedades originais das matérias-primas modificadas por meio de tratamento físico, químico ou biológico, ou ainda pela combinação destes métodos em processos que podem envolver a adição de ingredientes, aditivos ou coadjuvantes de tecnologia (Brasil, 2017). O consumo de carnes e derivados tem aumentado por ser uma fonte de minerais solúveis, vitaminas, gorduras essenciais, aminoácidos e muitos outros nutrientes com função específica no corpo (Kausar et al., 2021).

Os produtos cárneos se apresentam em uma grande variedade de categorias (Dolch et al., 2019). Como por exemplo almôndega, que é o produto cárneo obtido a partir de carne moída de uma ou mais espécies animais, moldado na forma arredondada, com adição ou não de ingredientes, e submetido a processo tecnológico específico, o hambúrguer que é obtido de carne moída das diferentes espécies animais, com adição ou não de ingredientes, moldado na forma de disco ou na forma oval e submetido a processo tecnológico específico, a linguiça que é obtida de carnes cominuídas das diferentes espécies animais, condimentado, com adição ou não de ingredientes, embutido em envoltório natural ou artificial e submetido a processo tecnológico específico, salsicha, presunto e etc. Os embutidos apresentam muita versatilidade, com maior atratividade, oportunidades de redução de desperdício e maior durabilidade, diferenciando-os no aspecto vida útil (shelf life) sobre as carnes 
frescas (Pintado \& Delgado-Pando, 2020).

A pecuária caprina é amplamente difundida em todo o mundo e sua importância pode aumentar no futuro para satisfazer a demanda de alimentos de uma crescente população mundial e a demanda por produtos de qualidade e saudáveis por parte do consumidor (Saccà, Corazzin, Bovolenta, \& Piasentier, 2019). O interesse pela carne caprina cresceu nesses últimos anos principalmente em virtude da sua composição, contendo proteínas e lipídios de boa qualidade, sendo considerada uma carne magra (Jia et al., 2021; da Silva Araujo et al., 2021). Em consequência desse crescimento no consumo e comercialização da carne caprina, as exigências do consumidor também se elevaram em relação à qualidade do produto, visando principalmente às suas propriedades nutritivas (Batista et al., 2019).

Segundo a Pesquisa da Pecuária Municipal (PPM) realizada pelo Instituto Brasileiro de Geografia e Estatística (IBGE) em 2019, a caprinocultura brasileira foi estimada em um rebanho de 11,3 milhões de cabeças, sendo que a maior concentração do rebanho está na região Nordeste com 10,7 milhões de cabeças (IBGE, 2019). Entretanto, possui grandes limitações nas ofertas de produtos diversificados, em que a qualidade atenda às exigências da população e dos diferentes mercados (Lima $e t$ al., 2021). As carnes de pequenos ruminantes como ovelhas, cabras, etc., são categorizadas como carnes vermelhas e têm maior aceitabilidade sensorial em comparação com as carnes brancas (Chauhan et al., 2021). Normalmente o mercado comercializa mais os animais jovens, fazendo com o que aqueles mais velhos percam valor econômico, podendo ser reaproveitados para elaboração de produtos cárneos (Rodrigues et al., 2019).

A crescente busca por alimentos saudáveis associada à valorização da cultura regional do Nordeste do Brasil, a carne caprina vem se apresentando com grande potencial tecnológico para o desenvolvimento de novos produtos cárneos, devido seu alto valor proteico, baixos níveis de gordura, colesterol e calorias, em relação à carne bovina e suína, atraindo o mercado de consumidores exigentes, e ao preparo de produtos cárneos (Queiroga et al., 2020).

Nesse contexto, o presente estudo tem como objetivo identificar através da literatura científica, o potencial tecnológico da carne caprina na elaboração de produtos cárneos, compreendendo quais as suas influências sobre as características físico-químicas e sensoriais desses alimentos.

\section{Metodologia}

Este estudo propõe uma revisão narrativa. Segundo a literatura, revisões do tipo narrativa são de natureza qualitativa, com finalidade de descrever o estado da arte de um determinado assunto, possibilitando uma discussão ampliada, crítica e pessoal dos autores (Iser et al., 2020). A pesquisa foi realizada de artigos que tratassem do assunto escolhido, propriedades da carne caprina e a utilização na elaboração de produtos cárneos, nas bases de dados Science Direct, PubMed e Google acadêmico no mês de maio de 2021. Para a pesquisa foram utilizados os seguintes termos de busca: "sausage" OR "meat products" AND "goat meat".

Para fins de seleção, foram considerados apenas artigos que fossem de pesquisa (não revisões científicas), disponibilizados na íntegra, gratuitos e que tivessem sido publicados entre os anos de 2019 a 2021 . Além disso, foram excluídos aqueles trabalhos que fossem duplicados, que não se encontrassem no período de publicação indicado e também não fossem artigo de pesquisa.

A primeira busca resultou em um total de 1.756 trabalhos sendo, 1.660 encontrados no Google académico, 90 no Science Direct e 6 no PubMed. Para a seleção dos artigos foram usados critérios de inclusão e exclusão e aplicação de filtros. O primeiro filtro utilizado foi a leitura dos títulos, o segundo foi a leitura dos resumos e por último a leitura do texto completo e assim foram selecionados 8 artigos, sendo 2 pertencentes ao PubMed, 2 ao Science Direct e 4 ao Google acadêmico. Com os artigos selecionados, foram realizadas análises aprofundadas para assim discutir as informações apresentadas pelos autores. 


\section{Resultados e Discussão}

No Quadro 1 são apresentados os artigos selecionados, identificados conforme a referência, título traduzido, objetivos e resultados alcançados de cada artigo.

Quadro 1: Análise dos artigos selecionados.

\begin{tabular}{|c|c|c|c|c|}
\hline$D^{1}$ & Referência $^{2}$ & Título Original & Objetivo & Resultados Alcançados \\
\hline A1 & $\begin{array}{c}\text { Teixeira; } \\
\text { Almeida; } \\
\text { Pereira; } \\
\text { Mangachaia e } \\
\text { Rodrigues } \\
\text { (2019) }\end{array}$ & $\begin{array}{c}\text { Physicochemical } \\
\text { characteristics of sheep } \\
\text { and goat pâtés. } \\
\text { differences between fat } \\
\text { sources and proportions }\end{array}$ & $\begin{array}{c}\text { Elaborar patês, feitos com carne } \\
\text { de ovelha e cabra, com adição de } \\
10 \% \text { e } 30 \% \text { de azeite ou barriga } \\
\text { de porco, e analisar a influência } \\
\text { da espécie, fonte de gordura e } \\
\text { percentual de gordura nas } \\
\text { características físico-químicas dos } \\
\text { produtos. }\end{array}$ & $\begin{array}{l}\text { Os patês ovino e caprino elaborados não } \\
\text { apresentaram diferenças significativas para } \\
\text { as porcentagens de proteína, gordura ou } \\
\text { colágeno. Foi observado um baixo teor de } \\
\text { gordura dos patês produzidos }(9,7-18,2 \%) \text { e } \\
\text { um teor de proteína muito alto variando de } \\
22-24 \% \text { em comparação com outros } \\
\text { produtos de carne semelhantes. }\end{array}$ \\
\hline A2 & $\begin{array}{c}\text { da Silva Araujo } \\
\text { et al. }(2021)\end{array}$ & $\begin{array}{l}\text { Reduction of sodium } \\
\text { content in frozen goat } \\
\text { sausage using different } \\
\text { types of salt }\end{array}$ & $\begin{array}{l}\text { Avaliar o efeito da substituição do } \\
\mathrm{NaCl} \text { por sal do Himalaia e outros } \\
\text { sais de cloreto, como } \mathrm{KCl}, \\
\mathrm{CaCl}_{2} \text { e } \mathrm{MgCl}_{2} \text {, nas } \\
\text { características físico-químicas, } \\
\text { microbiológicas e sensoriais de } \\
\text { linguiça de cabra congelada. }\end{array}$ & $\begin{array}{l}\text { A substituição do } \mathrm{NaCl} \text { por } \mathrm{KCl} \text { a } 50 \% \text { ou } \\
\text { uma mistura de } \mathrm{KCl} \text { a } 25 \%, \mathrm{MgCl}_{2} \text { a } 20 \% \text { e } \\
\mathrm{CaCl}_{2} \text { a } 5 \% \text { reduziu o teor de sódio da } \\
\text { salsicha de cabra em } 17,6 \% \text {, e o uso de sal } \\
\text { do Himalaia não reduziu o teor de sódio da } \\
\text { linguiça de cabra em comparação com o sal } \\
\text { comum. Foi observado também que a } \\
\text { redução do sódio pela substituição do } \mathrm{NaCl} \\
\text { por sais de cloreto nos níveis estudados não } \\
\text { influenciou negativamente nas } \\
\text { características físico-químicas, } \\
\text { microbiológicas e sensoriais da linguiça de } \\
\text { cabra congelada. }\end{array}$ \\
\hline $\mathbf{A 3}$ & $\begin{array}{c}\text { Chauhan et al. } \\
\text { (2021) }\end{array}$ & $\begin{array}{l}\text { In-vitro functional } \\
\text { efficacy of extracts } \\
\text { from Phyllanthus } \\
\text { emblica, Eucalyptus } \\
\text { globulus, Tinospora } \\
\text { cordifolia } \text { as pancreatic } \\
\text { lipase inhibitor and } \\
\text { source of anti-oxidant in } \\
\text { goat meat nuggets }\end{array}$ & $\begin{array}{l}\text { Avaliar a eficácia funcional } \\
\text { de frutos de Phyllanthus } \\
\text { emblica, folhas de Eucalyptus } \\
\text { globulus, caules de Tinospora } \\
\text { cordifolia quanto à atividade de } \\
\text { inibição da lipase pancreática e } \\
\text { efeito antioxidante em nuggets de } \\
\text { carne de cabra. }\end{array}$ & $\begin{array}{l}\text { Os extratos de plantas apresentaram } \\
\text { atividade inibidora da lipase pancreática e } \\
\text { potencial antioxidante e é comprovado que } \\
\text { extratos de plantas podem ser incorporados } \\
\text { como inibidores naturais da lipase } \\
\text { pancreática e fonte de antioxidantes em } \\
\text { produtos de carne vermelha. }\end{array}$ \\
\hline A4 & $\begin{array}{l}\text { Ivanović et al. } \\
\qquad(2020)\end{array}$ & $\begin{array}{l}\text { Influence of breed on } \\
\text { selected quality } \\
\text { parameters of fresh goat } \\
\text { meat }\end{array}$ & $\begin{array}{l}\text { Examinar algumas características } \\
\text { físicas, químicas e sensoriais da } \\
\text { carne caprina de diferentes raças. }\end{array}$ & $\begin{array}{l}\text { Na comparação dos resultados dos } \\
\text { parâmetros de qualidade da carne analisados } \\
\text { de cabras Balkan, Alpine e Saanen, foram } \\
\text { medidas diferenças significativas na } \\
\text { umidade, gorduras totais, proteínas, cinzas, } \\
\text { cor definida instrumentalmente e na } \\
\text { avaliação sensorial da carne. Além disso, } \\
\text { foram determinadas diferenças nos ácidos } \\
\text { graxos e no perfil de voláteis da carne. Os } \\
\text { resultados sugerem que a raça tem impacto } \\
\text { na qualidade da carne caprina e, portanto, } \\
\text { potencialmente na qualidade de seus } \\
\text { produtos. }\end{array}$ \\
\hline
\end{tabular}




\begin{tabular}{|c|c|c|c|c|}
\hline A5 & $\begin{array}{l}\text { Amaral et al. } \\
\qquad(2020)\end{array}$ & $\begin{array}{l}\text { Low fat goat meat } \\
\text { sausage with chitosan- } \\
\text { glucose Maillard } \\
\text { reaction product: impact } \\
\text { on quality and shelf life }\end{array}$ & $\begin{array}{l}\text { Elaborar salsicha de cabra com } \\
\text { baixo teor de gordura, } \\
\text { adicionando quitosana (controle) } \\
\text { e complexo de quitosana-glicose } \\
\text { e estabelecer o efeito sobre a } \\
\text { qualidade, estabilidade e prazo de } \\
\text { validade do produto armazenado } \\
\text { a } 4{ }^{\circ} \mathrm{C} \text { durante } 21 \text { dias por meio } \\
\text { da avaliação dos parâmetros } \\
\text { microbiológicos, físico-químicos } \\
\text { e sensoriais. }\end{array}$ & $\begin{array}{l}\text { Os resultados deste estudo mostraram que o } \\
\text { complexo quitosana-glicose pode ser } \\
\text { utilizado de forma eficaz para estender a } \\
\text { vida de prateleira de salsichas de cabra } \\
\text { frescas armazenadas em condições de frio. } \\
\text { Foi observada redução do crescimento } \\
\text { microbiano nas amostras tratadas, quando } \\
\text { comparado com a amostra de } \\
\text { controle. Além disso, as linguiças de cabra } \\
\text { in natura adicionadas do complexo } \\
\text { resultaram na melhor qualidade tecnológica, } \\
\text { pois proporcionou uma melhoria na } \\
\text { estabilidade, pela capacidade de ligar água e } \\
\text { gordura, além de textura mais firme, sem } \\
\text { influências negativas nas qualidades } \\
\text { sensoriais das amostras. }\end{array}$ \\
\hline A6 & $\begin{array}{l}\text { Wang et al. } \\
\text { (2019) }\end{array}$ & $\begin{array}{c}\text { Comparison of } \\
\text { Differential Flavor } \\
\text { Metabolites in Meat of } \\
\text { Lubei White Goat, } \\
\text { Jining Gray Goat and } \\
\text { Boer Goat }\end{array}$ & $\begin{array}{l}\text { Traçar o perfil dos metabólitos } \\
\text { em carne derivada de cabras } \\
\text { brancas Lubei, cabras Boer e } \\
\text { cabras cinzas Jining por } \\
\text { cromatografia líquida não } \\
\text { direcionada-espectrometria de } \\
\text { massa (LC-MS), para identificar } \\
\text { metabólitos de sabor. }\end{array}$ & $\begin{array}{c}\text { Os dados revelaram diferenças } \\
\text { significativas entre raças nas concentrações } \\
\text { de ácidos graxos, aldeídos, cetonas, } \\
\text { lactonas, flavonóides, fenólicos, alcalóides e } \\
\text { contaminantes de drogas, que podem } \\
\text { contribuir para os atributos sensoriais gerais } \\
\text { das amostras de carne por meio de } \\
\text { diferentes mecanismos. }\end{array}$ \\
\hline A7 & $\begin{array}{l}\text { Kausar et al. } \\
\qquad(2021)\end{array}$ & $\begin{array}{l}\text { Optimum Additive } \\
\text { Composition to } \\
\text { Minimize Fat in } \\
\text { Functional Goat Meat } \\
\text { Nuggets: A Healthy } \\
\text { Red Meat Functional } \\
\text { Food }\end{array}$ & $\begin{array}{l}\text { Determinar o nível ideal de } \\
\text { adição de folhas de feno-grego e } \\
\text { casca de psyllium para reduzir o } \\
\text { conteúdo de gordura em produtos } \\
\text { de carne de cabra, e determinar o } \\
\text { efeito da digestibilidade do } \\
\text { colesterol em nuggets de carne } \\
\text { otimizadas in vitro. }\end{array}$ & $\begin{array}{l}\text { Aditivos funcionais ideais podem aumentar } \\
\text { substancialmente o valor nutricional de um } \\
\text { produto alimentício processado sem } \\
\text { qualquer efeito significativo no sabor / } \\
\text { textura / vida útil. Um modelo digestivo } \\
\text { humano simulado in vitro sugeriu um } \\
\text { melhor gerenciamento do colesterol para o } \\
\text { produto final com ingredientes funcionais } \\
\text { ideais. A composição dos nuggets de carne } \\
\text { de cabra com aditivos funcionais ótimos } \\
\text { (FL e PH) foi prescrita e validada com } \\
\text { sucesso. }\end{array}$ \\
\hline A8 & $\begin{array}{l}\text { Resosemito et } \\
\text { al. }(2021)\end{array}$ & $\begin{array}{l}\text { Formulação, } \\
\text { preparação, e avaliação } \\
\text { sensorial de } \\
\text { hambúrguer da carne de } \\
\text { caprinos de descarte } \\
\text { com diferentes teores de } \\
\text { gordura }\end{array}$ & $\begin{array}{c}\text { Elaborar e avaliar sensorialmente } \\
\text { hambúrguer de carne caprina } \\
\text { elaborados com animais de } \\
\text { descarte e diferentes teores de } \\
\text { gordura. }\end{array}$ & $\begin{array}{l}\text { Os hambúrgueres da carne caprina de } \\
\text { animais de descarte tiveram uma boa } \\
\text { aceitação pelos consumidores, que foi } \\
\text { demonstrada pelo perfil de atitude dos } \\
\text { julgadores e frequência de compra, sendo } \\
\text { que a formulação com } 20 \% \text { de gordura } \\
\text { apresentou-se maior índice de preferência. } \\
\text { A preparação dos hambúrgueres da carne de } \\
\text { caprinos de descarte é uma opção para as } \\
\text { indústrias que queiram aproveitar } \\
\text { totalmente a carne caprina utilizando cortes } \\
\text { considerados menos nobres, como recortes } \\
\text { resultantes da desossa na fabricação de um } \\
\text { novo produto buscando agregação de valor. }\end{array}$ \\
\hline
\end{tabular}

1 - Identificação do artigo;

2 - Menção aos autores dos artigos.

Fonte: Autores (2021). 


\subsection{Características da carne caprina}

Produtores e consumidores estão demonstrando interesse cada vez maior pela carne de cabra, uma vez que os animais possuem pequenas quantidades de gordura subcutânea e intramuscular, sendo mais magra que a carne de origem bovina e cordeiro (Ivanović et al., 2020; Kausar et al., 2021). Ivanović et al. (2020), ressaltam que, nutricionalmente, a carne de cabra é uma fonte importante de proteínas de alta qualidade, gorduras saudáveis, baixas calorias, gorduras intramusculares, gorduras saturadas e sódio.

Ivanović et al. (2020), estudaram algumas características físicas, químicas e sensoriais da carne caprina de diferentes raças, onde caprinos balcânicos, alpinos e Saanen foram criadas durante o mesmo período e tinham cerca de 4 anos de idade no abate. A carne de caprinos balcânicos apresentou teor de 74,32\% para umidade, 3,82\% para gordura, 19,45\% para proteínas e 0,96\% para cinzas. Os caprinos alpinos apresentaram teor de 74,55\% para umidade, 3,90\% para gordura, 19,52\% para proteínas e $0,98 \%$ para cinzas. Para a carne de caprinos Saanen os teores de umidade, gordura, proteínas e cinzas foram de $74,77 \%, 4,05 \%, 19,82 \%$ e $1,01 \%$ respectivamente, com isso pode-se observar diferenças nos teores de umidade, gordura, proteínas e cinzas na carne entre as raças de caprinos, sendo algo de grande relevância na hora da escolha do animal a ser abatido para consumo (Ivanović et al., 2020).

Resosemito et al. (2021), falam que as características da carne que contribuem na "palatabilidade" são aquelas agradáveis aos olhos, nariz e paladar, dentre as quais sobressaem os aspectos organolépticos de sabor e de suculência e que tais propriedades podem ser influenciadas por diversos fatores, os quais exercem forte influência na qualidade e na quantidade das gorduras.

A qualidade da carne caprina pode ser afetada por vários fatores como a raça, o gênero, a produtividade, adaptação ao estresse, o ambiente, o manejo, a nutrição, o peso vivo e o peso da carcaça no abate (Ivanović et al., 2020). E em relação ao sabor, semelhante ao cordeiro, a carne de cabra cozida produz um sabor complexo que é único em comparação a outros tipos de carne vermelha. Embora esse sabor certamente sirva de base gastronômica para o amplo apelo da carne de cabra em todo o mundo, ele pode ser considerado de caça ou mesmo desagradável para os não acostumados (Wang et al., 2019).

O sabor é um atributo sensorial crítico da carne e é amplamente considerado um dos fatores mais importantes relacionados à sua qualidade e apelo do cliente. $\mathrm{O}$ sabor da carne caprina pode variar com as diferentes raças desses animais. A avaliação sensorial realizada por Wang et al. (2019), mostrou que a carne caprina pode apresentar mais sabor de caça e doce e até um maior nível de amargor.

Wang et al. (2019), falam que além de lipídios e ácidos graxos, compostos de carbonila voláteis, incluindo cetonas e lactonas, também desempenham papéis importantes em conferir um aroma único e atributos de sabor em produtos de carne. O autor ressalta ainda que os aldeídos e cetonas produzidos a partir da oxidação de lipídios costumam ser os principais contribuintes para o aumento do ranço da carne, pois muitos deles tendem a produzir sabores fortes e desagradáveis. No seu estudo Wang et al. (2019), encontraram variações nos níveis de antioxidantes entre os diferentes grupos experimentais que podem resultar em diferentes características de sabor ao afetar a composição de lipídios e outros compostos carbonílicos. Também deve ser apontado que muitos ácidos fenólicos e flavonóides são eles próprios amargos ou adstringentes, o que pode alterar ainda mais os atributos sensoriais dos produtos cárneos (Wang et al., 2019).

\subsection{Utilização da carne caprina na elaboração de produtos cárneos}

A carne caprina pode ser utilizada na elaboração de produtos cárneos como salsichas, linguiças, nuggets, patês e hambúrgueres (Teixeira, Almeida, Pereira, Mangachaia, \& Rodrigues, 2019; Amaral et al., 2020; da Silva Araujo et al., 2021; Chauhan et al., 2021; Resosemito et al., 2021). Existe um grande potencial no nicho mercadológico individual para carne processada de ovinos e caprinos, contudo, as descrições das propriedades e características dos produtos resultantes, podem ser 
excludentes ao consumidor, inviabilizando o crescimento no mercado de carnes (Teixeira et al., 2019).

Da Silva Araujo et al. (2021), estudaram a redução do teor de sódio em linguiça de cabra congelada com diferentes tipos de sal, e esse estudo mostrou que o uso de diferentes tipos de sal na linguiça caprina não apresentou diferenças para os teores de umidade, proteína e gordura entre salsichas, e não houve diferenças entre os tratamentos para capacidade de retenção de água e valores de atividade de água, não afetaram os valores de $\mathrm{pH}$ das salsichas, não apresentou efeito sobre os parâmetros instrumentais de cor da linguiça que é um dos principais atributos para a intenção de compra de produtos cárneos. Amaral et al. (2020), desenvolveram salsichas caprinas frescas com baixo teor de gordura à base de quitosana e quitosana derivada, objetivando produzir um alimento funcional. Além disso, avaliaram o efeito da inclusão desses compostos na qualidade, estabilidade e prazo de validade. Os autores demonstraram que o complexo de quitosana-glicose apresentou eficácia na vida de prateleira de salsichas de cabra frescas armazenadas sob condições de resfriamento. Além disso, os autores ressaltam que as linguiças de cabra in natura com derivado de quitosana apresentaram melhor qualidade tecnológica com aumento na estabilidade, capacidade de ligar água e gordura e, textura mais firme.

Teixeira et al. (2019), elaboraram um estudo sobre as características físico-químicas de patês de ovinos e caprinos e diferenças entre fontes de gordura e proporções, utilizando patês feitos com carne de ovelha e cabra, com 10\% e 30\% de porcentagem de azeite ou barriga de porco, não foram encontradas diferenças significativas para as porcentagens de proteína, gordura ou colágeno entre os patês e ainda foi observado um baixo teor de gordura dos patês produzidos $(9,7-18,2 \%)$ e um teor de proteína muito alto variando de 22-24\% em comparação com outros produtos de carne semelhantes, assim esses patês mostram ser uma forma interessante de valorizar animais de baixíssimo valor comercial.

Chauhan et al. (2021) desenvolveram nuggets de carne de cabra com a adição de frutos de Phyllanthus emblica (Sarandi), folhas de Eucalyptus globulus (eucalipto-comum), caules de Tinospora cordifolia (semente lunar com folhas de coração), afim de avaliar a eficácia quanto à atividade de inibição da lipase pancreática e efeito antioxidante, o estudo demonstrou que extratos de plantas podem ser incorporados como inibidores naturais da lipase pancreática e fonte de antioxidantes em produtos de carne vermelha de conveniência, e assim, até mesmo a salubridade dos produtos de carne vermelha pode ser garantida usando esses antioxidantes naturais à base de plantas e medidas anti-lipídicas.

Kausar et al. (2021), realizaram um estudo que planeja determinar o nível ideal de folhas de feno grego e casca de psyllium para reduzir o conteúdo de gordura em produtos de carne de cabra e determinar o efeito da digestibilidade do colesterol em nuggets de carne otimizados in vitro, no estudo o teor de gordura dos nuggets de carne de cabra foi mantido abaixo de $4 \%$ com uma combinação otimizada de aditivos funcionais (folhas de feno grego e casca de psyllium) e a relação sinérgica desses dois aditivos funcionais mostrou-se um critério eficaz para sua aplicação como atenuadores do teor de gordura em formulações de carne caprina, os estudos mostram ainda que o conteúdo de cinzas do nuggets aumentou com o aumento do conteúdo de carne de cabra e folha de feno grego, mas, o aumento na casca de psyllium não afetou significativamente o conteúdo de cinzas, o mesmo mostrou que a adição de casca de psyllium e folhas de feno grego melhorou significativamente o conteúdo de fibra dos nuggets de carne de cabra.

Resosemito et al. (2021) elaboraram hambúrgueres de carne caprina de animais de descarte com diferentes teores de gordura, testaram três formulações, com as misturadas com respectivamente $10 \%, 15 \%$ e $20 \%$ de toucinho do valor inicial da carne. Os autores observaram que a carne de caprinos de descarte tem pouca aceitação na forma in natura, em virtude do sabor e odor característicos, além da pouca maciez. No entanto, são ótima fonte proteica e de fácil adaptabilidade tecnológica no processamento cárneo na forma de hambúrgueres. A análise sensorial realizada mostrou que a formulação com $20 \%$ de toucinho foi considerada a melhor amostra quanto ao sabor, cor, odor, aparência e textura seguida pelas amostras dos tratamentos com $15 \%$ e $10 \%$ de toucinho, e em relação ao índice de aceitabilidade para a formulação com $20 \%$ de toucinho foi de $87,67 \%$, em seguida da formulação com $72,7 \%$, tais destaque foi devido a presença da gordura na formulação. Com isso, os 
autores demonstraram que a carne caprina de descarte pode ser uma matéria prima de baixo custo, com potencial tecnológico para a elaboração de hambúrgueres, permitindo o máximo aproveitamento das carnes pós-abate, diversificando o nicho dos produtos processados, agregando valor a subprodutos e contribuindo para a melhoria de renda de pequenos produtores.

\section{Conclusão}

Os artigos apresentaram o enorme potencial tecnológico da carne caprina, através do desenvolvimento e estudos sobre diferentes produtos cárneos processados. Além disso, foi possível compreender as características da carne caprina sobre diferentes tipos de processamentos e interações com outros ingredientes de forma a garantir e melhorar suas qualidades sensoriais, nutricionais e segurança alimentar. Contudo, a exploração dessa matéria prima ainda é muito restritiva e atrelada a fatores culturais e regionais, associado ao pequeno mercado de consumidores. Além disso, são necessários mais estudos na área de P \& D (Pesquisa e Desenvolvimento) para produtos cárneos caprinos, de forma que eles possam ser melhor explorados e valorizados em termos de mercado, sociedade, indústria e cultura.

\section{Referências}

Amaral, D. S. D., Cardelle-Cobas, A., Dias, C. D. C. Q., Lima, D. A. S., Pereira, S. D. F., Arcanjo, N. M. D. O., \& Dalmás, P. S. et al. (2019). Low fat goat meat sausage with chitosan-glucose Maillard reaction product: impact on quality and shelf life. Food Science and Technology, 40, 132-139. http://dx.doi.org/10.1590/fst.34018

Brasil (2017). Decreto $n^{\circ}$ 9.013, de 29 de março de 2017. Regulamento da inspeção industrial e sanitária de produtos de origem animal. Diário Oficial da União. Brasília, DF, 01 de jun. 2017, Seção 1, pág. 2.

Batista, P. B., Rodrigues, E. A., de Albuquerque, Í. R. R., Pessoa, E. N., de Carvalho, J. A. G., Ferreira, S. B., \& Veloso, M. V. R., et al. (2019). Caracterização do consumo e comercialização de carnes caprina e ovina na região de São Raimundo Nonato-Piauí. Brazilian Journal of Animal and Environmental Research, 2(4), 1237-1241. https://www.brazilianjournals.com/index.php/BJAER/article/view/2580

Botinestean, C., Hossain, M., Mullen, A. M., Kerry, J. P., \& Hamill, R. M. (2021). The influence of the interaction of sous-vide cooking time and papain concentration on tenderness and technological characteristics of meat products. Meat Science, 177, 108491. http://dx.doi.org/10.1016/j.meatsci.2021.108491

Chauhan, P., Kumar, R. R., Mendiratta, S. K., Talukder, S., Gangwar, M., Sakunde, D. T., \& Meshram, S. K. (2021). In-vitro functional efficacy of extracts from Phyllanthus emblica, Eucalyptus globulus, Tinospora cordifolia as pancreatic lipase inhibitor and source of anti-oxidant in goat meat nuggets. Food Chemistry, 348, 129087. http://dx.doi.org/10.1016/j.foodchem.2021.129087

da Silva Araujo, D. H., de Souza Rodrigues, R. T., da Costa, M. M., de Miranda, J. O., de Lira-Alencar, N. R. C., Queiroz, M. A. Á., de Alencar, M. G. et al. (2021). Reduction of sodium content in frozen goat sausage using different types of salt. $L W T, 135,110272$. http://dx.doi.org/10.1016/j.lwt.2020.110272

Dolch, K., Judas, M., Schwägele, F., \& Brüggemann, D. A. (2019). Development and validation of two triplex real-time PCR systems for the simultaneous detection of six cereal species in processed meat products. Food Control, 101, 180-188. http://dx.doi.org/10.1016/j.foodcont.2019.02.025

Iser, B. P. M., Sliva, I., Raymundo, V. T., Poleto, M. B., Schuelter-Trevisol, F., \& Bobinski, F. (2020). Definição de caso suspeito da COVID-19: uma revisão narrativa dos sinais e sintomas mais frequentes entre os casos confirmados. Epidemiologia e Serviços de Saúde, 29, e2020233. https://doi.org/10.5123/S167949742020000300018

Ivanović, S., Pavlović, M., Pavlović, I., Tasić, A., Janjić, J., \& Baltić, M. Ž. (2020). Influence of breed on selected quality parameters of fresh goat meat. Archives Animal Breeding, 63(2), 219-229. http://dx.doi.org/10.5194/aab-63-219-2020

Jia, W., Shi, Q., \& Shi, L. (2021). Effect of irradiation treatment on the lipid composition and nutritional quality of goat meat. Food Chemistry, 351 , 129295. http://dx.doi.org/10.1016/j.foodchem.2021.129295

Kausar, T., Kausar, M. A., Khan, S., Haque, S., \& Azad, Z. R. (2021). Optimum additive composition to minimize fat in functional goat meat nuggets: A healthy red meat functional food. Processes, 9(3), 475. http://dx.doi.org/10.3390/pr9030475.

Lima, R. F., da Silva, E. V., Paiva, Y. F., de Freitas, P. V. C., de Santana, A. G., da Silva França, K. R., \& Amadeu, L. T. S. et al. (2021). Hambúrguer caprino enriquecido com diferentes concentrações de albumina: Aspectos físicos e físico-químicos. Research, Society and Development, 10(4), e1510413828e1510413828. https://doi.org/10.33448/rsd-v10i4.13828

Pintado, T., \& Delgado-Pando, G. (2020). Towards more sustainable meat products: Extenders as a way of reducing meat content. Foods, 9(8), 1044. http://dx.doi.org/10.3390/foods 9081044

Queiroga, V. T. F., dos Santos Costa, S., da Nóbrega Albuquerque, T., de Santana, A. G., Silva, M. G., Marques, I. R., \& de Albuquerque Meireles, B. R. L. (2020). Oxidative stability of goat hamburger added with black sesame extract. Research, Society and Development, 9(10), e5349108623-e5349108623. $10.33448 /$ rsd-v9i10.8623. 
Research, Society and Development, v. 10, n. 9, e4810917648, 2021

(CC BY 4.0) | ISSN 2525-3409 | DOI: http://dx.doi.org/10.33448/rsd-v10i9.17648

Resosemito, F. S., Morais, J. C. Q., Queiroz, T. L. S., da Silva Ferreira, F. D. C., Belfort, C. F. T., Lopes, H. E. S., \& Sousa, A. E. C. et al. (2021). Formulação, preparação, e avaliação sensorial de hambúrguer da carne de caprinos de descarte com diferentes teores da gordura. Brazilian Journal of Development, 7(1), 4790-4797. http://dx.doi.org/10.34117/bjdv7n1-325

Rodrigues, S., Almeida, S., Pereira, E., \& Teixeira, A. (2019). How does the added fat source affect sensory quality of sheep and goat pâtés?. Ciência Rural, 49(5). https://doi.org/10.1590/0103-8478cr20190029

Saccà, E., Corazzin, M., Bovolenta, S., \& Piasentier, E. (2019). Meat quality traits and the expression of tenderness-related genes in the loins of young goats at different ages. Animal, 13(10), 2419-2428. http://dx.doi.org/10.1017/s1751731119000405

Teixeira, A., Almeida, S., Pereira, E., Mangachaia, F., \& Rodrigues, S. (2019). Physicochemical characteristics of sheep and goat pâtés. differences between fat sources and proportions. Heliyon, 5(7), e02119. http://dx.doi.org/10.1016/j.heliyon.2019.e02119

Wang, W., Sun, B., Hu, P., Zhou, M., Sun, S., Du, P., \& Ru, Y. et al. (2019). Comparison of differential flavor metabolites in meat of Lubei White Goat, Jining Gray goat and Boer goat. Metabolites, 9(9), 176. http://dx.doi.org/10.3390/metabo9090176

Xue, S., Wang, C., Kim, Y. H. B., Bian, G., Han, M., Xu, X., \& Zhou, G. (2020). Application of high-pressure treatment improves the in vitro protein digestibility of gel-based meat product. Food chemistry, 306, 125602. http://dx.doi.org/10.1016/j.foodchem.2019.125602. 